\title{
ROLE OF PERIOPERATIVE ANTIBIOTICS IN ELECTIVE LOW RISK CHOLECYSTECTOMIES IN PREVENTION OF SURGICAL SITE INFECTIONS
}

\author{
Prateek Sood ${ }^{1}$, Atul Mahajan², S. C. Jaryal ${ }^{3}$, Satish Kumar ${ }^{4}$, Kirti Rana ${ }^{5}$, Rohit Kumar', Amit Dogra ${ }^{7}$, Raj Kumar ${ }^{8}$
}

1 1Junior Resident, Department of Surgery, Dr. RPGMC, Tanda, Himachal Pradesh, India.

2 Professor, Department of Surgery, Dr. RPGMC, Tanda, Himachal Pradesh, India.

3 Professor, Department of Microbiology, Dr. RPGMC, Tanda, Himachal Pradesh, India.

${ }_{4}^{4}$ Assistant Professor, Department of Surgery, Dr. RPGMC, Tanda, Himachal Pradesh, India.

5Junior Resident, Department of Surgery, Dr. RPGMC, Tanda, Himachal Pradesh, India.

6Junior Resident, Department of Surgery, Dr. RPGMC, Tanda, Himachal Pradesh, India.

7 Junior Resident, Department of Surgery, Dr. RPGMC, Tanda, Himachal Pradesh, India.

8Junior Resident, Department of Surgery, Dr. RPGMC, Tanda, Himachal Pradesh, India.

\section{BACKGROUND}

ABSTRACT

Cholecystectomy is the universally accepted method to manage symptomatic uncomplicated cholelithiasis and other benign gallbladder diseases, because it can cure the disease and has low morbidity and mortality. The most frequent complication in patients undergoing cholecystectomy is surgical site infection. Cholecystectomy is considered clean-contaminated if the biliary tract is entered without significant spillage during the procedure. Some randomised clinical trials have confirmed that antibiotic prophylaxis in open cholecystectomy is decreasing the risk of surgical site infection.

\section{MATERIALS AND METHODS}

Randomised studies have failed to demonstrate the effectiveness of routinely administered perioperative antibiotics on SSI in these low and moderate risk groups and there is growing consensus against it. Many authors believe that antibiotic prophylaxis may not be necessary for low-risk patients undergoing elective cholecystectomies.

\section{RESULTS}

The present study was aimed to observe if antibiotic prophylaxis is necessary to prevent SSIs in the patients undergoing elective below-risk cholecystectomies.

\section{CONCLUSION}

Our study found no significant difference in the rates of SSI in low-risk laparoscopic cholecystectomies with or without the use of perioperative antibiotics.

\section{KEY WORDS}

Laparoscopic Cholecystectomy, Surgical Site Infection, Methicillin-Resistant Staphylococcus aureus.

HOW TO CITE THIS ARTICLE: Sood P, Mahajan A, Jaryal SC, et al. Role of perioperative antibiotics in elective low risk cholecystectomies in prevention of surgical site infections. J. Evolution Med. Dent. Sci. 2018;7(27):3099-3102, DOI: $10.14260 /$ jemds/2018/696

\section{BACKGROUND}

Surgical site infection significantly contributes to surgical morbidity and mortality every year. It denotes infection at or near surgical incision within 30 days of surgery. It accounts for almost $15 \%$ of all nosocomial infections and represents the most common nosocomial infection. ${ }^{1}$ Post-operative infections lead to increased hospital stay, incurring escalated expenses, increased number of hospital readmissions and jeopardised health outcomes.

Most common source of pathogen is the native flora of patient's skin, mucosal surfaces or hollow viscus. On breach of skin, underlying tissue is exposed to overlying endogenous flora. Most commonly aerobic gram positive cocci such as Staphylococcus sp serve as the main contaminant with

'Financial or Other Competing Interest': None.

Submission 23-04-2018, Peer Review 14-06-2018,

Acceptance 20-06-2018, Published 02-07-2018.

Corresponding Author:

Dr. Atul Mahajan,

Anand Bhawan, Dane Road,

Dharamshala District, Kangra-176215,

Himachal Pradesh, India.

E-mail: dratulmahajan@yahoo.co.in

DOI: $10.14260 /$ jemds $/ 2018 / 696$ resistant pathogens such as methicillin resistant $\mathrm{S}$. aureus (MRSA) denoting increased number of such infection in recent times. ${ }^{2,3}$ Breach of hollow viscous exposes surrounding tissues to gram negative bacilli such as E. coli, gram positive organisms such as Enterococci and occasionally anaerobes such as Bacillus fragilis.

Cholecystectomy is a globally accepted standard method to manage cholelithiasis and other benign gall bladder diseases, since it is curative and carries low morbidity and mortality. Common complication undergoing cholecystectomy is surgical site infections. SSIs were reported in $10 \%$ to $23 \%$ of the patients who had been operated on before the routine use of antibiotic prophylaxis was introduced in 1960.4

Since 1960, antibiotic prophylaxis has been considered as the best intervention to prevent surgical site infection in elective surgery. Antibiotic prophylaxis includes preoperative administration of wide-spectrum antibiotics against the most frequent bacteria involved in surgical site infection, trying to get high tissue levels of the antibiotic at the surgical wound in order to avoid colonisation and growth of microorganisms. It is accepted that antibiotic prophylaxis must be administered in all surgical procedures classified as clean-contaminated or in selected patients undergoing clean procedures. Cholecystectomy is considered clean-contaminated on the 
basis that the biliary tract is entered without significant spillage during the procedure. Some randomised clinical trials have confirmed that antibiotic prophylaxis in open cholecystectomy is decreasing the risk of surgical site infection. Randomised studies have failed to demonstrate the effectiveness of routinely administered perioperative antibiotics on SSI in these low and moderate risk groups and there is growing consensus against it. Many authors believe that antibiotic prophylaxis may not be necessary for low-risk patients undergoing elective cholecystectomies. The present study was aimed to observe if antibiotic prophylaxis is necessary to prevent SSIs in the patients undergoing elective low-risk cholecystectomies.

\section{MATERIALS AND METHODS}

This non-randomised controlled trial was conducted in the Department of Surgery, Dr. Rajendra Prasad Government Medical College, Kangra at Tanda, during one year period after approval from institutional protocol review and ethics committee. All patients hospitalised for elective cholecystectomy after fulfilling the exclusion and inclusion criteria during the period of one year were enrolled for the study after informed written consent. Sample size was decided on the basis of all patients hospitalised for elective cholecystectomy after fulfilling the exclusion and inclusion criteria. A detailed history, clinical examination and routine investigations were done in all patients and recorded.

All the patients of both genders between 12 and 60 years of age undergoing laparoscopic cholecystectomy during the period of one year were included in the study. Patients were divided into 2 groups by alternate method, so the study is nonrandomised controlled trial. Group A patients did not receive any perioperative antibiotics, while patients in Group B received perioperative antibiotics (cefuroxime + clavulanic acid). The first dose of antibiotic was given half an hour before skin incision. The second dose of antibiotic was not required in any of the patients. Exclusion criteria were patients who had undergone intervention (ERCP) previously, breach of sterilisation, bile spillage, accidental entry into biliary tract, GIT, urogenital system during surgery, patients with pyocele/empyema, acute pancreatitis, immunocompromised state diabetes mellitus, tuberculosis, on corticosteroid therapy, HIV+, hepatitis B+ and malignancy etc.; deranged coagulation profile, LFT's (liver function tests) and RFT's (renal function tests), patients in whom drain was kept intraoperatively, surgery duration more than 2 hours, pregnancy or lactation and refusal to provide consent.

All surgeries were done under general anaesthesia. Patients were advised bath with povidone-iodine surgical scrub $7.5 \% \mathrm{w} / \mathrm{v}$ early morning on the day of surgery and depilation with a depilatory cream. Parts were painted with povidone-iodine solution $10 \% \mathrm{w} / \mathrm{v} 3$ times followed by sterile draping before skin incision. The skin was closed with 3-0 nonabsorbable monofilament sutures preferably nylon. All aseptic precautions were taken during the perioperative period.

The dressing was opened on second postoperative day and done with appropriate size opsite dressing which was a transparent film with acrylic adhesive with moisture vapor permeability and is waterproof.

In patients with uneventful postoperative course, discharge of the patients from the hospital was done as early as possible in order to prevent nosocomial infection. All patients were followed daily till discharge, then after 7 days for suture removal and 4 weeks following surgery to evaluate the status of the wound and to look for signs and symptoms suggestive of any surgical site infection as per proforma. In the event of any postoperative surgical site wound infection, wound swab was sent for culture and antibiotic sensitivity in the Department of Microbiology. Postoperatively, patients were monitored daily for symptoms and signs of sepsis as per proforma.

Data were presented as frequency, percentage and Mean \pm SD. Student t-test was used to compare parametric quantitative variables between 2 groups. Chi-square test with or without Yate's correction was used to compare descriptive variables between the groups. Mann-Whitney U test was used to compare non-parametric variables between the groups. A pvalue $<0.05$ was considered significant. Statistical analyses were done using SPSS version 21.

\section{RESULTS}

The present study observed that patient's age was comparable in Group A when compared with Group B (40.21 \pm 10.63 vs. $40.71 \pm 11.18$; $\mathrm{p}=0.825$ ). Females outnumbered males with a ratio of 7.64: 1 . The present study also observed that there was no significant difference in sex between Group A and Group B $(\mathrm{p}=0.216)$ (Table 1).

Duration of preoperative pain (Days) was nonsignificantly higher in Group A when compared with Group B $(\mathrm{p}=0.373)$ (Table 2).

Our study observed that SSIs were present in 7 patients on post-operative Day 2, out of which 4 were present in Group A and 3 in Group B. Our study also observed that incidence of SSIs was non-significantly higher in Group A when compared with Group B ( $p=0.977)$ (Fig. 1). SSIs were not present in both groups on post-operative Day 7.

Our study also observed that in Group A there were 3 patients with SSI grade III and 1 patient with SSI grade II, while in group B there were 2 patients with SSI grade II and 1 patient with SSI grade III.

Duration of hospital stay was non-significantly higher in Group A (median/ IQR: 2.0/ 0.00) when compared with Group B (median/ IQR: 2.0/ 0.00) $(\mathrm{p}=0.190)$.

\begin{tabular}{|c|c|c|c|c|}
\hline \multicolumn{2}{|c|}{} & $\begin{array}{c}\text { Group A } \\
(\mathbf{n = 4 7 )}\end{array}$ & $\begin{array}{c}\text { Group B } \\
(\mathbf{n = 4 8 )}\end{array}$ & $\begin{array}{c}\text { Total } \\
(\mathbf{n = 8 5})\end{array}$ \\
\hline $\begin{array}{c}\text { Age } \\
\text { (Years) }\end{array}$ & Mean \pm SD & $\begin{array}{c}40.21 \pm \\
10.63\end{array}$ & $\begin{array}{c}40.71 \pm \\
11.18\end{array}$ & - \\
\hline \multirow{4}{*}{$\begin{array}{c}\text { Age- } \\
\text { Group }\end{array}$} & $\leq 20$ & $2(4.25 \%)$ & $1(2.08 \%)$ & $3(3.16 \%)$ \\
\cline { 2 - 5 } & $21-30$ & $7(14.9 \%)$ & $8(16.67 \%)$ & $15(15.79 \%)$ \\
\cline { 2 - 5 } & $31-40$ & $13(27.6 \%)$ & $16(33.33 \%)$ & $29(30.53 \%)$ \\
\cline { 2 - 5 } & $41-50$ & $17(36.1 \%)$ & $13(27.08 \%)$ & $30(31.58 \%)$ \\
\cline { 2 - 5 } Sex & $51-60$ & $8(17.02 \%)$ & $10(20.83 \%)$ & $18(18.95 \%)$ \\
\cline { 2 - 5 } & Male & $3(6.38 \%)$ & $9(18.75 \%)$ & $11(11.58 \%)$ \\
\cline { 2 - 5 } & Female & $44(93.32 \%)$ & $39(81.25 \%)$ & $84(88.42 \%)$ \\
\hline \multicolumn{5}{|c|}{ Table 1. Age and Sex (n=95) } \\
\hline
\end{tabular}

Group A (Patients who did not receive any preoperative antibiotics); Group B (Patients who received preoperative antibiotics). 


\begin{tabular}{|c|c|c|c|c|}
\hline & & $\begin{array}{c}\text { Group A } \\
(n=47)\end{array}$ & $\begin{array}{c}\text { Group B } \\
(n=48)\end{array}$ & $P$ value \\
\hline $\begin{array}{l}\text { Duration of } \\
\text { Pain (Days) }\end{array}$ & $\begin{array}{l}\text { Median; } \\
\text { IQR }\end{array}$ & $55.0 ; 59.0$ & $50.0 ; 45.0$ & 0.373 \\
\hline \multirow{2}{*}{ Acute Attack } & Yes & 16 & 20 & \multirow{2}{*}{0.444} \\
\hline & No & 31 & 28 & \\
\hline \multirow{2}{*}{ Jaundice } & Yes & - & - & \multirow[b]{2}{*}{ - } \\
\hline & No & 47 & 48 & \\
\hline
\end{tabular}

Group A (Patients who did not receive any preoperative antibiotics); Group B (Patients who received preoperative antibiotics).

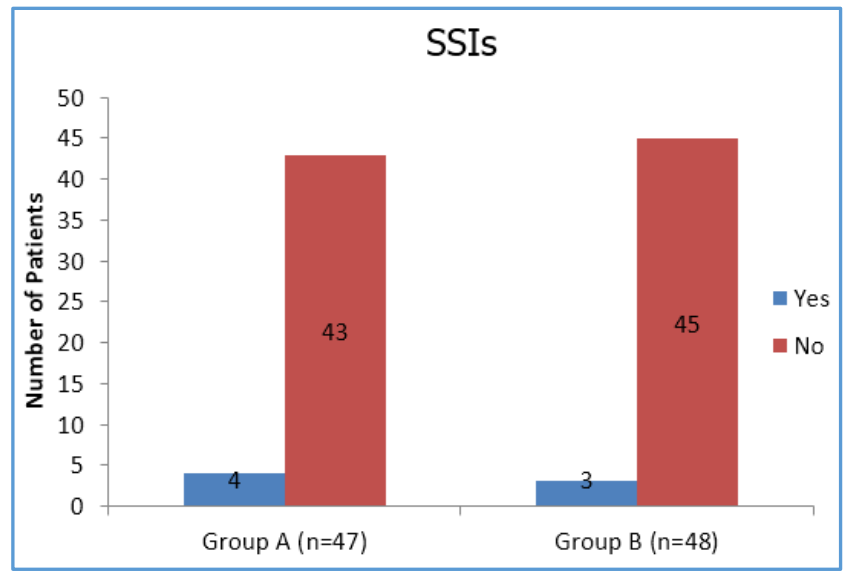

Figure 1. Surgical Site Infections (X-axis denotes number of patients; Y-axis denotes Group A (Patients who did not receive any Preoperative Antibiotics) and Group $B$ (Patients who received Preoperative Antibiotics)

\section{DISCUSSION}

A total of 95 patients were enrolled into the study after fulfilling the inclusion and exclusion criteria. In the present study, the incidence of SSI was $7.37 \%$. The average rate of SSIs for LC has been reported in the literature to be between $0.4 \%$ and $6.3 \%$. In a study by Uludag et al found the incidence of SSI was $3.47 \%$, which is lower than the rate found in our study. ${ }^{5}$ The high rate of SSI in our study could be attributable to our liberal definition of such infections.

Our study found that incidence of SSI was 8.5\% in Group A, while $6.25 \%$ in Group B. Our results are comparable to Sharma et al who observed the incidence rate to be $4 \%$ and $8 \%$ in the patients who received antibiotics and did not receive antibiotics respectively. ${ }^{6}$

Our study did not observe any statistically significant difference in the rate of SSI among Group A and B. It showed that a single dose of the combination of cefuroxime and clavulanic acid was not able to lower the rate of SSI. The findings are supported previously by Sharma et al who observed the similar findings with a single dose of ceftriaxone. ${ }^{6}$

There are a number of studies who have shown controversial results with the use of antibiotics in the prevention of SSIs. McGuckin et al retrospectively reviewed the records of 1,702 patients undergoing laparoscopic cholecystectomy (LC). They found an overall infection rate of $2.3 \%$ and a surgical-site infection rate of $0.4 \%$. Preoperative antimicrobial prophylaxis was received by $79 \%$ of patients, but only $33 \%$ of these received the agent within 1 hour or less prior to surgery. These facts suggested that antimicrobial prophylaxis may not be necessary for low-risk LC patients. ${ }^{7}$

Choudhary et al conducted a meta-analysis to evaluate the efficacy of prophylactic antibiotics in low-risk patients. (Those without cholelithiasis or cholangitis) undergoing laparoscopic cholecystectomy. A total of 20 articles were included in the meta-analysis. They concluded that prophylactic antibiotics prior to laparoscopic cholecystectomy resulted in no statistically significant benefit for total infections, superficial infections, major infections, distant infections and reduction of hospital stay. ${ }^{8}$

Since in the present study, we have excluded the patients with co-morbidities such as diabetes, hypertension etc. It could also be one of the reasons of no significant effect of antibiotics in the prevention of SSIs.

We also evaluated SSI on the basis of modified Southampton grading scheme. Our study observed that erythema and other signs of inflammation were present in 3 patients (Grade II) and clear or haemoserous discharge was observed in 4 patients (Grade III). In the patients with grade III SSI, the wounds were laid open and a swab was sent for culture and antibiotic sensitivity. However, the swab revealed no growth of any micro-organisms after 48 hours of culture in all grade III SSIs. Daily dressings were done and secondary suturing was performed once the wound was clean on the 3rd postoperative day. Grade I, II, III and IV are superficial infections (CDC classification). None of the patients in our study developed deep or organ space infection. Kumar et al observed superficial infection in one patient. No deep or organ space infection was observed. ${ }^{9}$

\section{CONCLUSION}

Our study found no significant difference in the rates of SSI in low-risk laparoscopic cholecystectomies with or without the use of perioperative antibiotics. So, it can be concluded that the use of perioperative antibiotics can be avoided in low-risk cholecystectomies, so as to prevent the misuse of antibiotics.

\section{REFERENCES}

[1] Watanabe A, Kohnoe S, Shimabukuro R, et al. Risk factors associated with surgical site infection in upper and lower gastrointestinal surgery. Surg Today 2008;38(5):404-12.

[2] Urban JA. Cost analysis of surgical site infections. Surg Infect (Larchmt) 2006; (7 Suppl 1):S19-S22.

[3] de Lissovoy G, Fraeman K, Hutchins V, et al. Surgical site infection: incidence and impact on hospital utilization and treatment costs. Am J Infect Control 2009;37(5):387-97.

[4] Vegasi AA, Jodra VM, García ML. Nosocomial infection in surgery wards: a controlled study of increased duration of hospital stays and direct cost of hospitalization. Eur J Epidemiol 1993;9(5):504-10.

[5] Uludag M, Yetkin G, Citgez B. The role of prophylactic antibiotics in elective laparoscopic cholecystectomy. JSLS: J Soc Laparoendosc Surg 2009;13(3):337-41.

[6] Sharma N, Garg PK, Hadke NS, etal. Role of prophylactic antibiotics in laparoscopic cholecystectomy and risk factors for surgical site infection: a randomized controlled trial. Surg Infect (Larchmt) 2010;11(4):36770 . 


\section{Jemds.com}

[7] McGuckin M, Shea JA, Schwartz JS. Infection and antimicrobial use in laparoscopic cholecystectomy. Infect Control \& Hosp Epidemiol 1999;20(9):624-6.

[8] Choudhary A, Bechtold ML, Puli SR, et al. Role of prophylactic antibiotics in laparoscopic cholecystectomy: a meta-analysis. J Gastrointest Surg 2008;12(11):1847-53.

\section{Original Research Article}

[9] Kumar A, Patodia M, Pandove PK, et al. Role of antibiotic prophylaxis in laparoscopic cholecystectomy: a randomized prospective study. JIMSA 2013;26(4):20911. 